Natalia De Luca*

\title{
El marcador conversacional ahre en memes: hacia la definición del marcador-meme en interacciones digitales de dos comunidades de práctica juveniles
}

The conversational marker ahre in memes: towards the definition of the marker-meme in digital interactions of two youth communities of practice

https://doi.org/10.1515/soprag-2021-0008

Publicado en línea junio 18, 2021

Resumen: El presente artículo busca describir y analizar, desde un enfoque multimodal (Kress y van Leeuwen, 2001; Kress, 2005, 2009; Jewitt, 2009), las relaciones entre los marcadores del discurso (Martín Zorraquino y Portolés, 1999) y los memes (Knobel y Lankshear, 2005; Varis y Blommaert, 2015), a partir de una selección de memes que fueron compartidos en dos grupos de Whatsapp de estudiantes de dos escuelas secundarias de Buenos Aires. Para ilustrar esta relación, nos detendremos en el marcador ahre, marcador de gran frecuencia de uso en el habla de los estudiantes, con el fin de, en primer lugar, describir las funciones comunicativas que mantiene en los memes, y, en segundo lugar, indagar en qué medida este marcador desempeña solo una función discursiva verbal dentro del meme, o si se configura de manera autónoma como marcador-meme. Esta categoría novedosa y aporte de esta investigación nos permitirá evidenciar cómo un marcador oral puede constituirse en meme y, simultáneamente, cómo un meme puede funcionar como marcador en los intercambios en línea. Por último, discutiremos los resultados en torno al modal ontinuum (Tannen, 1982), y cómo los marcadores conversacionales en géneros digitales se inscriben como un recurso dentro del repertorio lingüístico de los estudiantes.

Palabras clave: Marcador del discurso, discursos digitales, marcadores meme, memes, multimodalidad

*Corresponding author: Natalia De Luca, Humanidades, UNSAM, San Martin, Argentina, E-mail: nataliaadeluca@gmail.com

¿ Open Access. ( 2021 Natalia De Luca, published by De Gruyter. (๔) BY-NC-ND This work is licensed under the Creative Commons Attribution-NonCommercial-NoDerivatives 4.0 International License. 
Abstract: This article aims to describe and analyze -from a multimodal approach (Kress and van Leeuwen, 2001; Kress, 2005, 2009; Jewitt, 2009) - the relationships between discourse markers (Martín Zorraquino and Portolés, 1999) and memes (Knobel and Lankshear, 2005; Varis and Blommaert, 2015). The corpus is composed of a selection of memes that were shared in two Whatsapp groups of students from two secondary schools in Buenos Aires. In order to illustrate this relationship, the focus is ahre, a discourse marker that is widely used in the students' speech. The purpose is, on the one hand, to describe the communicative functions that ahre presents in memes; on the other hand, to investigate to what extent this marker plays only a verbal discursive function within the meme or, on the contrary, it is configured autonomously as a marker-meme. This novel category constitutes a contribution of the present research since it permits to show how an oral marker can become a meme and, simultaneously, how a meme can function as a marker in online exchanges. The final discussion focuses on the results about the modal continuum (Tannen, 1982) and about the digital conversational markers as a resource of the students' linguistic repertoire.

Keywords: speech marker, digital speeches, meme markers, memes, multimodality

\section{Introducción}

Tanto los marcadores del discurso como el habla de comunidades de práctica juveniles (Eckert, 2006) ${ }^{1}$ han sido y siguen siendo objeto de interés de diversos estudios en el ámbito de la sociolingüística y del análisis del discurso. Este artículo busca describir y explorar las funciones comunicativas del marcador ahre desde un enfoque que trasciende la dicotomía tradicional entre oralidad-escritura y que, por el contrario, incorpora los estudios recientes del discurso multimodal. Desde este enfoque, los datos del corpus, memes compartidos en grupos de Whatsapp en los que aparece el marcador conversacional ahre, nos permiten repensar las relaciones entre diversos modos semióticos (la escritura, lo visual, lo gestual) fuera de las dicotomías oralidad/escritura o verbal/visual. Entendemos que en los entornos de

1 Destacamos que no deseamos hablar de los adolescentes o los jóvenes como una categoría general y como una comunidad idealizada, por el contrario, comprendemos que no son un grupo homogéneo. A tales efectos, consideramos pertinente referirnos como comunidades de práctica (Eckert, 2006), entendido como un grupo de personas que participan de manera continua en algún objetivo o esfuerzo en común. Las comunidades de práctica surgen en respuesta a intereses o posiciones comunes, y juegan un papel importante en la formación de la participación y orientación de sus miembros en el mundo que los rodea. 
comunicación digital esta polarización históricamente trazada como línea divisoria desde diversos enfoques y debates lingüísticos (Blanche-Benveniste, 1998; Cantamuto \& Vela Delfa, 2016; Cassany, 1989; Kress, 2003; Lyons, 1977; Ong, 1982) hoy se ha vuelto controvertida. En esta investigación, retomamos a Kress (2005) quien plantea que la naturaleza de los medios orales y de los medios escritos ha ido mutando, de hecho, las relaciones entre oralidad y escritura no son concebidas desde una perspectiva antagónica sino como un continuo modal (Tannen, 1982) que se reconfigura y actualiza constantemente en relación con otros modos semióticos según los contextos de situación y los contextos de cultura (Halliday, 1978). Existen diversas formas de producir, distribuir y comunicar significados y conocimientos que cuestionan las dicotomías modales y llevan a concebir un continuum (multi) modal que se resignifica y revitaliza en cada intercambio.

A partir de la indagación en entornos digitales, en especial, de cómo los marcadores dialogan con otros modos semióticos en un género discursivo particular, los memes, se intenta dar cuenta de la complejidad de los escenarios contemporáneos atravesados por las tecnologías de la información y comunicación. Así, además de una descripción de funciones comunicativas, se busca analizar si el marcador ahre puede simplemente encontrarse textualizado e integrar el meme de manera independiente junto con los otros modos; o, convertirse en un marcador-meme, categoría novedosa que intentaremos describir, y ser imagengesto-texto simultáneamente. El análisis multimodal de esta investigación requiere no solo detenerse en el estudio del lenguaje verbal, sino también en la integración con otros recursos que generan expansiones semánticas gracias a la potencialidad que cada modo ofrece. Los marcadores-meme a partir de su potencial semántico y multimodal logra erigirse, en el marco de las interacciones en línea de Whatsapp, como una respuesta lingüística a ciertas necesidades comunicativas, que en el caso del discurso digital, están influidos de forma directa por las características del medio (Cantamutto \& Vela Delfa, 2020).

\section{Marco Teórico: marcadores conversacionales y memes en entornos en línea}

Este artículo se organiza a partir de dos ejes teóricos convergentes: (a) el estudio y el análisis de los marcadores del discurso -en particular, de los marcadores conversacionales- a partir de los desarrollos de la Pragmática (Escandell Vidal, 1996; Portolés, 2004; Verschueren, 1999); (b) la Teoría Multimodal (Jewitt, 2009; Kress, 2005, 2009; Kress \& van Leeuwen, 2001). 


\subsection{Sobre los marcadores discurso: una aproximación teórica}

Los marcadores del discurso han constituido un objeto de investigación ampliamente estudiado desde diversos enfoques teóricos y metodológicos. Esto implica que no exista un criterio único para su denominación, su definición, sus propiedades, sus funciones y/o su clasificación. Los estudios pragmáticos de la última década han promulgado la necesidad de cimentar las investigaciones referidas a la comunicación en ejemplos reales situados en contexto y pertenecientes a un corpus de habla oral y digital. Existen vastos estudios que han abordado el estudio de marcadores conversacionales en el español de Argentina (Borzi, 2014; García Negroni, 2012, 2014). No obstante, existen investigaciones que se han centrado en usos de marcadores específicos por los adolescentes argentinos. Son relevantes los aportes de Kuguel (2014), quien ha estudiado las características de las variedades juveniles a partir de los rasgos morfológicos, léxicos y sintácticos en distintas investigaciones y, además, ha mencionado que no existen estudios sociolingüísticos extendidos ni detallados sobre el habla juvenil en Argentina.

Di Tullio and Kornfeld (2013) profundizaron el estudio de marcadores del discurso (como manzana o de una) utilizados por adolescentes; así también, Kornfeld $(2013,2014)$ se centró en las expresiones utilizadas (particularmente entre los jóvenes) medio, onda y tipo. Otra arista posible de estos antecedentes son aquellas investigaciones que se centraron en estudiar los marcadores conversacionales en discursos digitales (Cantamutto, 2013; Lorendo \& Picone, 2012; Mancera Rueda \& Placencia, 2011). La investigación abordada en este artículo cobra relevancia porque, si bien como mencionamos previamente existen estudios de marcadores del discurso en interacciones juveniles, no así se hallan estudios académicos específicos que se centren en el uso de ahre.

Para esta investigación, tomamos como punto de partida la definición de marcadores conversacionales, establecida por Martín Zorraquino and Portolés (1999) y caracterizados como aquellos que aparecen con frecuencia en la conversación, es decir, una situación comunicativa peculiar, con propiedades específicas, que determina o favorece la presencia de una serie de marcadores. Este tipo de marcador se encuentra dentro de la categoría macro de marcadores del discurso y que reúne algunas características fundamentales: (a) desde el punto de vista prosódico, se encuentran limitados como incisos por la entonación del habla oral, se percibe una pausa posterior al marcador $\mathrm{y}$, a veces, también una anterior; mientras que, en la escritura, la entonación se refleja habitualmente situando el marcador entre comas, aunque en algunas ocasiones el signo de puntuación puede estar ausente; (b) morfológicamente, son unidades lingüísticas invariables que pertenecen a diferentes categorías gramaticales; (c) sintácticamente, son 
unidades no integradas en la oración con un grado de autonomía que, según estos autores, varía para cada marcador; además, no presentan una posición fija y tampoco pueden recibir especificadores ni adyacentes complementarios; (d) por último, desde el aspecto semántico, son elementos que evidencian un significado de procesamiento, es decir, guían de acuerdo con sus distintas propiedades morfosintácticas, semánticas y pragmáticas, las inferencias que se han de efectuar del conjunto de los dos miembros discursivos que conectan (Martín Zorraquino \& Portolés, 1999, p. 4057).

Estos rasgos permiten caracterizar al marcador ahre desde una dimensión pragmático-semántica (Martín Zorraquino \& Portolés, 1999) y, por la tanto, describir las funciones discursivas-comunicativas que desempeña este marcador, atravesadas tanto por el significado de los marcadores como por el papel que estos cumplan en los intercambios comunicativos. En particular, a partir de los datos relevados para esta investigación, se observó que este marcador puede cumplir tres funciones discursivo comunicativas diferentes: (a) función reparadora, que desrealiza el contenido semántico de lo que se dice previamente; (b) función metalingüística, que propone una reflexión sobre el lenguaje empleado y evidencia la conciencia lingüística de estos estudiantes; y (c) una función intensificadora, que sirve para reforzar la intención comunicativa en algunos enunciados. Esta perspectiva supone un estudio pragmático pues nos permite describir la relación que se establece entre las distintas formas lingüísticas y sus usos.

\subsection{Sobre los memes en interacciones en línea: una aproximación teórica}

De los intercambios en Whatsapp emergen usos del marcador conversacional ahre entrelazado con usos de memes virales o de circulación vernácula en cada grupo. Desde la década de 1960, el meme ha sido abordado por diferentes disciplinas. La primera referencia se encuentra en el libro El gen egoísta (1976) del biólogo Richard Dawkins. Dawkins propuso esta categoría para referirse a frases, conductas o melodías populares que, en cada cultura, se difunden y se replican por imitación de una generación a la siguiente, como una unidad de sentido cultural. Esta replicación implica la reiteración del uso del meme en múltiples contextos y por diferentes personas, así comienza a construir un acervo con capacidad de persistir a lo largo del tiempo y del espacio, que empieza a consolidarse como parte de una cultura determinada en la que se comparten ciertos usos y significados. De esta manera, un meme contiene un significado compartido para aquellos que lo han 
incorporado en sus repertorios culturales (Pérez Salazar, 2017) y para aquellos que llevan a cabo su replicación, ya sea con modificaciones o sin ellas.

Para analizar la relación entre ambos recursos lingüísticos (marcadores y memes), en esta investigación apelamos a la definición de Blommaert (2015), para quien los memes constituyen un género semiótico multimodal. A pesar de su forma simple y replicable, son discursos complejos, compuestos por diferentes recursos modales, entre los que se combinan imágenes y textos (Varis \& Blommaert, 2015). Esta combinación multimodal posibilita una resemiotización intensa, ya que los signos originales se alteran de varias maneras (aunque a veces se mantiene un grado de reconocimiento de sustrato), pero se ajustan y alteran situacionalmente para producir efectos comunicativos diferentes. Generalmente, se presenta una característica definitoria de los memes de Internet que actúa como plantilla y brinda a los usuarios un molde preexistente para expresar nuevos pensamientos e ideas de una manera familiar. La viralidad y la repetición son dos características inherentes a este género discursivo multimodal en línea: los memes se replican como una forma de expresión identitaria y/o como una opinión con respecto a circunstancias determinadas. Estas son características compartidas con los marcadores conversacionales: ambos se basan en el mecanismo de réplica y son fácilmente reconocidos como unidades semántico-pragmáticas en diversas situaciones comunicativas (Magadán, 2021).

Knobel and Lankshear (2005) también sugieren que en la mayor parte de los memes en línea no se verifica una replicación de forma intacta, sino que suelen atravesar diversos procesos de reinterpretación y modificación; en otras palabras, si bien la idea esencial tiende a permanecer, su expresión concreta puede ser muy diversa en su forma. Incluso, distinguen, por un lado, entre memes estáticos, porque mantienen cierta fidelidad con respecto a algún meme genérico que actúa como molde y, por otro lado, los 'remezclados', los cuales retocan algunas características base y mutan con la intención de hacerlas más apropiadas para lograr un mayor impacto entre los receptores (Knobel \& Lankshear, 2005, p. 69). Esta clasificación resulta clave para nuestro análisis con el fin de observar el distinto grado de agentividad de los estudiantes: si actúan solamente como propagadores, si realizan algunos cambios a partir de una plantilla o si crean un meme completamente nuevo.

Por último, resulta clave pensar en cómo los memes crean los lazos identitarios entre los jóvenes a partir de su viralidad, en tanto funcionan como recursos para construir relaciones de alteridad con otros a través del humor y la sátira (Pérez Salazar, 2017). De hecho, la mayoría de los memes que se han vuelto virales lo han conseguido por su condición de relato global y por capacidad semántica de conectar diversas sensibilidades y realidades culturales heterogéneas. 


\section{Metodología de la investigación}

Los datos se desprenden de una experiencia realizada en dos cursos de Lengua y Literatura de nivel secundario en el ciclo orientado de escuelas privadas -una en la Ciudad Autónoma de Buenos Aires y otra en el Gran Buenos Aires-, a los que llamaremos de aquí en adelante Grupo Lanús y Grupo Pompeya y que están conformados por un total de 43 estudiantes de entre 15 y 18 años. Los nombres que se presentan a lo largo de esta investigación no son reales, sino que fueron cambiados para preservar el anonimato de los menores.

Se decidió explorar intercambios con los estudiantes en grupos de Whatsapp creados ad hoc, lo cual posibilitó observar cómo los marcadores que emplean en sus intercambios cotidianos son memeficados (algunos creados por ellos y otros de circulación masiva en línea) ${ }^{2}$, es decir, se convierte en meme en interacciones en línea. El objetivo del grupo era la reflexión sobre la lengua que tenía continuidad con una secuencia didáctica previa que se venía realizando en el aula: los diccionarios en línea y los colaborativos a partir de la búsqueda de marcadores conversacionales que ellos usaban en sus conversaciones orales espontáneas.

Los intercambios en el grupo de Whatsapp se extendieron durante dos meses en el año 2020. En los grupos, los estudiantes compartieron, y en ocasiones comentaron, 21 memes: 6 sobre el marcador ahre (que fueron todos seleccionados para este estudio), 5 sobre el marcador tipo y otros que no establecían vínculo con ningún marcador discusivo del español. El hecho de que las interacciones se extendieran durante un tiempo prolongado generó un clima de espontaneidad en el que los alumnos también pudieron compartir reflexiones sobre usos emergentes del lenguaje y también otros memes que creaban y con los que se encontraban a diario. A fin de centrarnos en este estudio, solo nos detendremos en el marcador ahre en el contexto de memes, pero cabe destacar que este marcador también se presentó de manera muy recurrente en el marco de las interacciones y no solo en memes.

En cuanto al enfoque metodológico, decidimos apelar al relevamiento de datos a través de una etnografia virtual (Hine, 2000) con el objeto de investigar y observar la aparición y el uso de los marcadores conversacionales en pantallas y descubrir, a partir de preguntas semidirigidas y también de conversaciones

2 Los estudiantes fueron invitados a la creación de este grupo y accedieron voluntariamente a formar parte de él; otorgaron los permisos correspondientes (tanto de manera individual como de sus padres mediante un consentimiento informado) y fueron informados sobre el objetivo de cada grupo: la charla y reflexión sobre la lengua, en especial, los usos de los marcadores conversacionales en entornos digitales. Cabe aclarar que, si bien sabían que esas charlas podrían formar parte de los datos de esta investigación, sus respuestas en ningún caso serían evaluadas, ya que los alumnos habían completado los cursos en cuestión. 
espontáneas, sus vínculos con el género meme (Varis \& Blommaert, 2015), así como su relación con diversos modos semióticos. En este sentido, la etnografía digital se constituye como una metodología ideal para iniciar esta clase de estudios, en la medida en que puede servir para explorar las complejas interrelaciones existentes entre las aserciones que se vaticinan sobre las nuevas tecnologías en diferentes contextos (Hine, 2000, p. 13).

\section{Análisis}

\subsection{Ahre en los memes: ¿qué funciones comunicativas mantiene el marcador?}

Detenerse en los memes compartidos en los dos grupos de Whatsapp revela, en particular, que el marcador ahre es ampliamente usado en ambas comunidades de práctica y que representa una marca identitaria y distintiva del estilo lingüístico de cada grupo. Dentro del repertorio de recursos con el que cuentan estos estudiantes, al ahre emerge de manera viral y recurrente en sus conversaciones. Ahora bien, en los memes, su uso no expresa siempre la misma función comunicativa pues ciertas regularidades discursivas halladas permiten delimitar tres funciones orientadas a objetivos comunicativos diferentes: (a) función reparadora, (b) función metapragmática, y (c) función intensificadora. A continuación, organizamos el análisis de los usos de ahre en los diálogos en torno a estas tres funciones (Ilustraciónes 1 y 2):
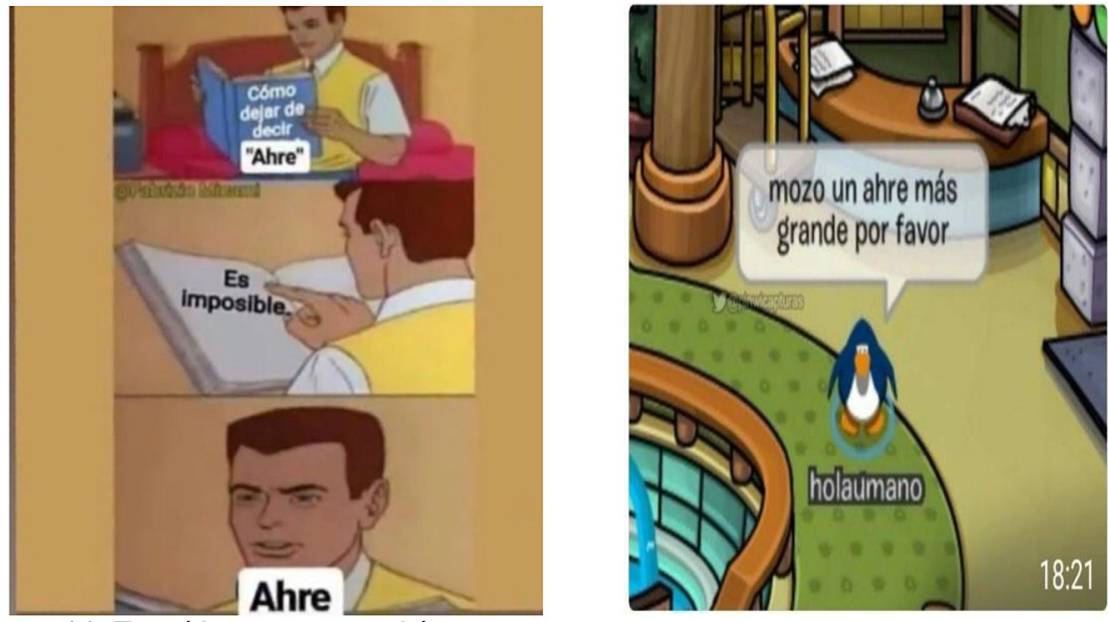

(a) Función metapragmática:

Ilustración 1: Meme \#1 aportado por Lucía del Grupo Pompeya.

Ilustración 2: Meme\#2 aportado por Camila del Grupo Pompeya. 
Tanto en Meme\#1 como en Meme\#2 el ahre sirve para realizar reparaciones dialectales que toman la forma de un comentario metalingüístico que se usa para indicar la presencia de otra voz y para adoptar características de esta en sus interacciones (Bonnin, 2014). En otras palabras, el marcador ahre funciona para realizar un comentario metapragmático, que supone una reflexión sobre el lenguaje empleado y evidencia la conciencia metapragmática de los hablantes. Algunos autores (Portolés, 2004; Verschueren, 1999) mencionan que todos los hablantes poseen la capacidad de conciencia de uso de la lengua en un contexto determinado para configurar el texto y convertirlo adecuado a la situación comunicativa a partir de elecciones lingüísticas conformes a cada momento.

El Meme\#1 presenta el marcador ahre como un contenido metalingüístico y se propone enseñar a los interlocutores cómo se usa. En este sentido, su función discursiva en el intercambio resulta metapragmática y descansa en un conocimiento compartido de los códigos lingüístico y retórico (Alvarado \& Yeannoteguy, 1999) entre los participantes de esa conversación en Whatsapp para lograr el efecto humorístico esperado. Este meme presenta una composición visual desarrollada de manera tripartita y narrada como una sucesión de actos. En el primer cuadro, se observa a un hombre consultando en un manual cómo dejar de decir ahre; en segundo lugar, se muestra la respuesta (Es imposible) y, en tercer lugar, el cierre con el ahre satiriza la situación preexistente, querer dejar de usarlo, pero no poder hacerlo. El marcador es empleado en dos momentos de esta narración con dos funciones discursivas diferentes: la primera, metapragmática, en tanto sirve como objeto de reflexión acerca de sus usos en el sistema de la lengua; la segunda, intensificadora, en tanto refuerza el enunciado anterior -Es imposible-y produce el efecto cómico e irónico en el juego dicotómico entre el intentar eliminarlo y el uso incontrolable del marcador.

El ahre se convierte en objeto de reflexión metalingüística y presenta una situación autorreferencial que experimentan estos hablantes: el deslizamiento entre marcador y muletilla del marcador ahre en sus interacciones cotidianas. Con un valor paródico se muestra que el marcador ahre configura un rasgo estilístico clave de sus prácticas: entre lo que ellos hacen (usar ahre desmesuradamente) y lo que ellos creen que deberían hacer (abandonar su uso, tal como lo señala la perífrasis dejar de usar) (Halliday, 1978). También, la ilustración de búsqueda en un manual y la inclusión de la pregunta presentan al libro como fuente de consulta y saber lingüístico reconocido académicamente ante un interrogante que requiere una mirada prescriptiva y una instrucción sencilla para adecuarse a una variedad estándar.

También, el Meme\#2 propone una reflexión metalingüística sobre el marcador $\mathrm{y}$, en ese sentido, revela una función metapragmática del meme en el curso de la conversación en Whatsapp. La imagen plantea un guiño intertextual con el 
videojuego multijugador en línea Club Penguin, en el que se construye un mundo virtual con pequeños pingüinos como personajes principales y que permite interactuar con jugadores de todo el mundo. El modo visual nos brinda la información contextual mediante la ilustración de la barra de bar en el marco de un espacio amplio y abierto al público. El modo verbal expresa el acto de pedido a través de las formas de cortesía (por favor) y de un vocativo explícito (mozo). El globo del diálogo, ubicado espacialmente en el centro del meme, funciona como texto organizador y el ahre, despojado de sus características de marcador (ya parte de un sintagma nominal: un ahre más grande) orientan al interlocutor a comprender que el marcador es un recurso de la lengua que puede ser requerido de manera semejante a otro trago en un bar (Ilustraciónes 3-5).
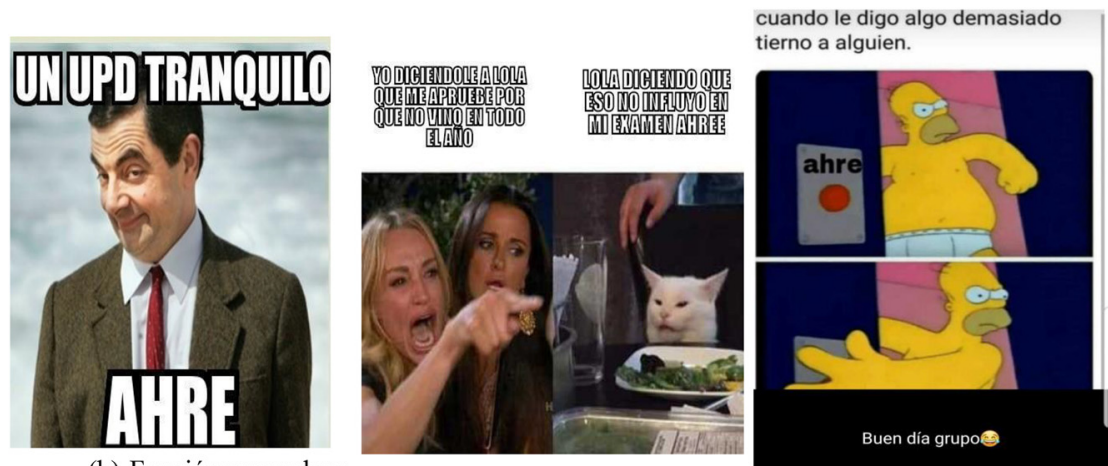

(b) Función reparadora

Ilustración 3: Meme\#3 aportado por Franco del Grupo Lanús. Ilustración 4: Meme\#4 aportado por Camila del Grupo Pompeya. Ilustración 5: Meme\#5 aportado por Oriana del Grupo Lanús.

También, el marcador ahre funciona como una reparación del contenido semántico del enunciado previo. El concepto de reparación proviene del campo del análisis de la conversación y refiere al tratamiento de un problema en un uso interactivo de la lengua (Liddicoat, 2007), es decir, todo hablante en un diálogo puede marcar una emisión como problemática y puede proponer que un elemento posterior funcione como corrección o intento de solución del problema. Esta función ha aparecido la mayoría de los memes y ha sido ampliamente usada y compartida: de 12 memes, 6 han sido con esta función reparadora, 4 con función intensificadora y 2 con función metapragmática.

El Meme\#3 se enmarca en una conversación sobre un evento compartido por los estudiantes del último año de la escuela secundaria en la Argentina: el festejo 
del último primer día de clase (UPD). ${ }^{3}$ Para comentar este evento, el Meme\#3 presenta diversos modos que interactúan en el texto: el visual, el gestual y el verbal. Desde la imagen se presenta al clásico personaje inglés Mr. Bean, que se muestra desde su prolijidad en la vestimenta haciendo un gesto cómplice que apela al receptor del meme. Este abre con una invocación a la tranquilidad del evento mencionado, pero que no es compatible con los gestos y con el cierre del ahre. El texto ahre se configura como un signo indicial que repara el texto previo (ubicado en la parte superior del meme) y, junto con el gesto, orienta hacia una interpretación contraria al enunciado impreso arriba, en la imagen. Para que la función comunicativa se logre, se necesita un conocimiento del contexto local (qué es un UPD y cómo suelen ser estos eventos), es decir, ni meme ni marcador podrían ser interpretados en cualquier situación puesto que apuntan a una experiencia concreta y compartida por estos hablantes en particular.

En el Meme\#4, los estudiantes también usan el marcador ahre con una función reparadora, pero la comprensión del meme requiere un conocimiento intragrupal del contexto: formar parte de la comunidad de práctica, saber quién es Lola, cómo son sus clases, cuál es la relación entre la docente y sus alumnos, etc. En la imagen, los estudiantes imitan la secuencia narrativa de planos televisivos que invita a leer una temporalidad con el fin de recrear con tintes humorísticos una situación compartida de su escena escolar. Los planos de izquierda y derecha se tornan relevantes en la composición semiótica (Kress \& van Leeuwen, 2001) para narrar concretamente lo ocurrido apoyándose en varios modos: la tensión es acompañada por el modo gestual a partir de los rasgos de sufrimiento, acusación, lágrimas, la boca que sugiere gritos y el dedo acusador del lado izquierdo; mientras que del lado derecho se presenta la templanza del gato, el poder, la vertiente emocional ante la situación crítica por el modo visual y gestual, así como también una representación de la prosodia que le da duración a la imagen a través del alargamiento vocálico final del marcador. El valor desrealizante de ahre repara lo enunciado (Lola diciendo que eso no influyó en mi examen) y reorienta la interpretación de los interlocutores burlándose de que las faltas reiteradas de una docente a clase no afectan el aprendizaje de los estudiantes.

En el Meme\#5, la función discursiva reparadora también se activa a partir de una secuencia, esta vez inspirada en el personaje de Homero Simpson. El botón ahre anuncia la posibilidad de desrealizar lo previamente enunciado (el decir cosas demasiado tiernas) y al activarse el botón se deshace la acción enunciativa anterior. La posibilidad de reparación se visualiza en la combinación del modo visual y el

3 En los últimos años, se convirtió en Argentina una tradición, para quienes están cursando el último año del ciclo lectivo de la escuela secundaria, compartir la noche anterior y realizar un festejo. 
modo verbal: el botón/marcador de color rojo que simboliza alerta, precaución y salida. El modo gestual de Homero acompaña esta doble sensación de asombro y enojo pues se lo percibe enfadado y con el brazo extendido para activar el botón/ marcador con la necesidad comunicativa de remendar lo dicho. También, el texto superior invita a realizar una lectura metapragmática, en tanto brinda un ejemplo a los interlocutores de en qué casos se puede pulsar y usar el botón/marcador ahre. La presencia de ese texto superior hace que el marcador se vuelva contextodependiente; mientras que la secuencia de imágenes por sí solas (botón ahre desactivado/activado) permitiría que pueda usarse en diversas situaciones comunicativas como un imagen-gesto-texto (comodín) reparador. Esta función reparadora se presenta como un rasgo estructurador e indicial, centrado en el enunciatario, en tanto orienta la lectura hacia atrás (el evento tema del meme) y hacia adelante (el gesto y la interpretación pragmática).

Esta función reparadora en los memes apela a la construcción de una afiliación identitaria en tanto proyectan un evento común (el UPD, las situaciones particulares con docentes en la escuela y los vínculos sentimentales entre pares) que resulta reconocible entre los participantes del intercambio y que, a través de la reparación con el marcador, los acerca aún más en la experiencia compartida y en su visión de mundo sobre ella.

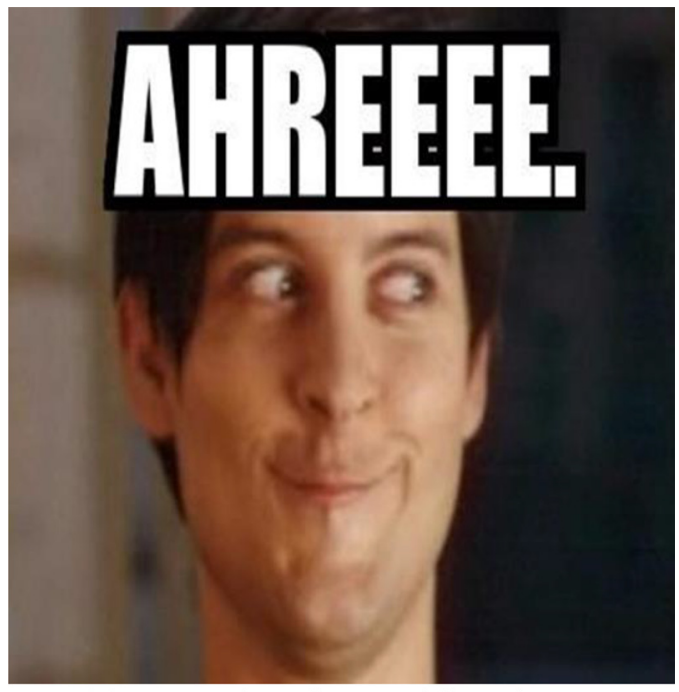

(c) Función intensificadora
Ilustración 6: Meme\#6 aportado por Franco del Grupo Lanús.

Además, de las dos funciones anteriormente presentadas, en el siguiente meme se evidencia uso intensificador y reforzador que produce el empleo del marcador 
ahre. Siguiendo la definición de Briz (1998), la intensificación es una estrategia pragmática que imprime mayor fuerza y puntos de vista propios o ajenos, ya sea coincidentes o contrarios, y que en el ámbito social se desempeña como mecanismo de refuerzo, ya sea valorizador o amenazante de la imagen propia o ajena. Como analizaremos a continuación, en el Meme\#6 el marcador ahre se despliega con una función intensificadora En este meme se retoma una imagen viral del actor estadounidense Tobey Maguire para representar, mediante la cohesión de diversos modos, que se dirá algo irónico o con doble sentido. Por un lado, el modo gestual prepondera en la imagen a partir del revoleo de ojos y de la mirada cómplice del actor y, por otro lado, el modo verbal a través del ahre, con una extensión eeee representa la prosodia e intensifica la suspicacia del modo gestual y la desrealización de cualquier posible interpretación literal de un mensaje. Teniendo en cuenta que no se dirige a alguna situación o evento en particular, este meme actúa como comodín para ser utilizado en múltiples conversaciones, al modo de stícker, ${ }^{4}$ y para enviarlo como respuesta en diversas situaciones comunicativas con el fin de dar fuerza y destacar la imagen de quien envía el meme o stícker ya sea desde el acercamiento de un código endogrupal identitario compartido o ya sea desde el distanciamiento con los otros.

Los memes analizados hasta el momento (\#1 a \#6) revelan que la acción de viralización implica distintos grados de intervención y manipulación de los usuarios en los memes (entendidos no solo como imitación de otros memes sino como textos que activan el agenciamiento de estos hablantes). A diferencia de la lingüística estructural que proponía la noción de arbitrariedad de los signos lingüísticos, según la cual la relación entre el significante y el significado no era constitutiva sino convencional, en estos memes entendidos como composiciones multimodales se evidencia que existe una motivación entre el significante y el significado que expresa: cuando los hablantes recurren a cada modo, lo consideran el más apto y adecuado para expresar el sentido que quieren comunicar (Kress, 2005). Desde la Teoría Multimodal (Jewitt, 2009; Kress, 2005, 2009; Kress \& van Leeuwen, 2001), los signos son construidos o reconstruidos dentro de la semiótica social ya que los hablantes los (re)crean, demarcando sus significados al utilizarlos en contextos disímiles con fines concretos. De hecho, esta relación de motivación ${ }^{5}$ entre el

4 Los stícker son pegatinas que desde el 2018 han comenzado a ser protagonistas en las conversaciones en línea de la plataforma Whatsapp. Tal como se expresa desde la página oficial de la plataforma, la función principal es ofrecer la posibilidad de expresar con stícker lo que no siempre se logra hacer con palabras. Si bien no son objeto de esta investigación, los jóvenes han manifestado en las entrevistas focales en línea que suelen usarlos constantemente y que los marcadores también son protagonistas en estos.

5 La relación de motivación entre significante y significado solamente discute la agentividad de los sujetos en la elección de los signos y en su capacidad de significar. 
significante y el significado es la clave para que el meme funcione comunicativamente a partir de la elección del hablante de cada recurso semiótico fundado en las potencialidades de cada modo y del género discursivo.

Estos memes se diferencian según los grados de agentividad que desempeñan los estudiantes. Por ejemplo, en el Meme\#4, debieron elegir una plantilla, una imagen, etc., para recrear el meme en función de una nueva situación comunicativa. Su producción se genera a partir de múltiples recursos semióticos que dialogan con diversos productos visuales culturales: escenas de películas, dibujos animados, imágenes virales creadas por otros usuarios (Shifman, 2014), que son apropiados y resignificados con el fin de producir sentido en determinados contextos comunicativos y que terminan por trascender la imagen, el texto o la plantilla original del meme. En esta línea, resultan relevantes los aportes de Shifman (2013), quien reconoce que existen memes ready-made (Shifman, 2013). Estos son memes en grado cero que no demandan ninguna transformación previa a su uso en tanto solo deben encajar en un contexto dado, tales como \#Meme2 o Meme\#6. De hecho, son pensados como memes que navegan y pueden compartirse sin ninguna modificación, pues ya se presentan como unidades semánticas completas y discretas. En contraposición, los más contextuales (Shifman, 2013) cuentan con un alcance limitado: a veces, no pueden ser reutilizados porque fueron creados y modificados para una situación particular e incluso pierden sentido en algunos intercambios cuando no pueden ser comprendidos por los destinatarios, tal como sucede en (Meme\#1, Meme\#3, Meme\#4).

\subsection{Ahre: ¿un marcador conversacional en memes o marcador- meme?}

La elección de estos memes indefectiblemente se vio motivada por la presencia del marcador ahre. No obstante, en cada uno de ellos el marcador no se comporta de la misma manera: mientras en algunos el marcador es un enunciado verbal que sirve para construir, como un modo semiótico más, la textualidad del meme; en otros el marcador cobra potencia como imagen-gesto-texto a partir de su composición multimodal y de su autonomía genérica como un marcador-meme que despliega el uso de algunas de sus funciones discursivas propias.

Tanto en el Meme\#1 como en el Meme\#2, la reflexión sobre el marcador ahre se produce exclusivamente a partir del texto y sobre la función comunicativa que este manifiesta (en este, caso la metapragmática). La imagen en ambos memes funciona como un soporte requerido por el género $\mathrm{y}$, a la vez, brinda el marco narrativo para crear el efecto humorístico; mientras que el modo verbal aporta el tema y la intención comunicativa sucinta principalmente en el marcador. En esta 
misma línea, sucede en el Meme\#4 en tanto la textualización verbal del marcador tiene el objeto de reparar lo enunciado en la secuencia narrativa bidimensional. En estos tres memes se evidencia la heterogeneidad constitutiva multimodal en el que cada modo aporta una significación parcial para la integración total de todos los modos en el mismo meme.

A diferencia de los anteriores, el Meme\#3, Meme\#5 y Meme\#6 se erigen como marcadores-meme, caracterizados como unidades semántico-pragmáticas multimodales compuestas por una combinación coherente y cohesiva de imagen-gestotexto en las que la potencia de lo visual-gestual no permite aislar el gesto de otros modos, como la imagen, lo verbal, etc. Así, estas unidades están disponibles para ser empleadas allí donde el intercambio invoque alguna de las funciones discursivas del marcador en cuestión.

Por ejemplo, en el Meme\#5 la acción/imagen de apretar un botón se vuelve indivisible al marcador que indica la reparación y que este podría emplearse de manera análoga en diversas situaciones comunicativas que requieran apretar un botón-marcador para reparar lo dicho. También, en el Meme\#6 el revoleo de ojos y el modo verbal a través del marcador sumado a la extensión vocálica que representa la prosodia se convierten en un trinomio semiótico-multimodal que encarna la reparación en su grado máximo. Ambos memes podrían desempeñarse al estilo de un comodín con el fin de ser usados en diferentes situaciones comunicativas dado que no tienen un anclaje contextual y particular delimitado, sino que son de carácter general y por tanto pueden ser empleados en múltiples situaciones comunicativas que requieran una reparación. Ahora bien, no todos los marcadores-meme son de carácter general, sino que también pueden ser de carácter más contextuales y creados por los usuarios sin perder de vista su condición. Esto ocurre con el Meme\#3 en el que el marcador-meme se utiliza para un evento específico de los hablantes (lo cual restringe su capacidad de uso) y se configura como un signo multimodal por su preeminencia gestual-verbal para representar comunicativamente.

A partir de los datos analizados, entonces, se observa que el marcador-meme en los intercambios de estas comunidades de práctica se erige, así como un recurso multimodal, dentro del repertorio de cada hablante, que puede insertarse en un intercambio conversacional. Dentro de esta categoría, observamos una gradación contextual que coincide en cierta medida con el esquema composicional: aquellas que toman como base una sola imagen de fondo y centradas en un gesto en primer plano, se corresponden a nuestra definición de marcador-meme; aquellos que presentan una estructura secuencial de planos narrativos debilitan el uso del marcador-meme por su carácter más restringido a usarlo con una función reparadora. De hecho, el análisis evidencia que los memes se constituyen como un género dinámico y productivo. Si bien los marcadores-meme pueden desempeñarse como una unidad inalterable que es citada, replicada y usada en diversas 
ocasiones, también se observa que muchas veces son modificados por los hablantes para activar una nueva función discursiva. En este sentido, los usuarios pueden ser meros viralizadores, o bien interlocutores activos que despliegan un dominio sólido del código género con distintos grados de intervención (en algunas ocasiones realizan ligeras modificaciones en los textos multimodales y en otras crean memes nuevos).

Los estudiantes de ambas comunidades de práctica se caracterizaron por su creatividad en la construcción de sus memes: lograron adaptar memes virales existentes a sus situaciones cotidianas y generaron un trabajo de resemiotización intenso (Scollon \& Scollon, 2004) que desplegaron en sus prácticas comunicativas escolares. Esta concepción dinámica de los géneros discursivos (Briggs \& Bauman, 1996) demuestra que el proceso por el cual se produce y recibe un género se puede encontrar mediatizado por discursos anteriores en una trama de relaciones intertextuales que, por una parte, “convierte a los géneros en entidades ordenadas, unificadas y delimitadas” y, por otra, en entidades “fragmentadas, heterogéneas y abiertas” (Briggs \& Baumann, 1996, p. 88). Un meme tiene características propias y definidas, pero también, como en el caso de los marcadores-meme, puede tener ecos de otros discursos y géneros. Además, como se evidenció en nuestro análisis, pueden presentar secuencias de planos televisivos o memes más narrativos o abiertos a un diseño y estructura no tan estable pero que tendrá las funciones delimitadas que provienen del marcador.

Todo hablante cuenta con un repertorio lingüístico heterogéneo que trasciende lo verbal y que incorpora lo multimodal. Así, un análisis multimodal requiere no solo detenerse en el estudio del lenguaje verbal, sino también en la integración con otros recursos que generan expansiones semánticas gracias a la potencialidad que cada modo ofrece. Existen diversas formas de producir, distribuir y comunicar significados y conocimientos que cuestionan las dicotomías modales y llevan a concebir un continuum (multi)modal que se resignifica y revitaliza en cada intercambio. Este continuum muestra, por un lado, que, de su repertorio, los hablantes eligen conscientemente los recursos en función de los géneros, y estas elecciones están íntimamente relacionadas con las funciones discursivas y con ciertas expectativas sobre sus interlocutores; por otro lado, que el repertorio es constitutivamente heterogéneo y que apela a una diversidad de recursos semióticos. El estudio de estos memes y marcadores evidencia esta heterogeneidad: algunas veces, un marcador se encuentra textualizado e integra por igual un meme junto con los otros modos; otras veces, a partir de la categoría rica de marcador-meme, encontramos que un marcador puede ser imagen-gesto-texto simultáneamente y materializa así la complejidad y la riqueza del repertorio lingüístico para configurar prácticas estilísticas (Eckert, 2004) identitarias de una comunidad. 


\section{Conclusiones}

En este artículo se ha explorado cómo las interacciones en línea no consisten en un simple intercambio de mensajes; por el contrario, se trascienden las formas de comunicación cara a cara y también de la comunicación escrita a partir de las relaciones entre los distintos modos y de la elección significativa que los hablantes/estudiantes de este estudio hacen de cada recurso semiótico. De hecho, las escenas tecnológicas contemporáneas habilitan el estudio de las relaciones entre los diferentes modos (oral, escrito, imagen, etc.) no ya como entidades aisladas sino como un continuum (multi)modal.

El análisis de la serie de seis memes, desde un enfoque pragmático-multimodal, nos permitió revelar cómo el marcador ahre es usado en intercambios conversacionales digitales con tres funciones discursivas diferentes: metapragmática, reparadora e intensificadora. Asimismo, el intercambio de memes habilitó un rasgo distintivo grupal: las elecciones de imágenes-meme re/conocidas (o no) por sus interlocutores, así como la referencia a eventos compartidos, sirvieron para construir y reforzar la empatía y la complicidad a partir de prácticas estilísticas que hacen a la pertenencia y a la cohesión identitaria grupal.

También el análisis permitió descubrir que el marcador puede configurarse como un modo semiótico particular, en este caso desde su materialidad verbal, o como un signo indicial que señala, desde su materialidad verbal, la imagen-gesto que condensa y refuerza la intención comunicativa. De esta manera, este estudio posibilitó observar cómo emerge un concepto clave que revela la existencia de un continuum multimodal: el marcador-meme. El ahre-meme cobró una materialidad propia en el chat, simultáneamente como meme (multimodal) y como marcador (orales/escritos). Lo verbal y lo visual convergieron en un texto y el marcador cobró potencia como imagen-gesto, casi como un stícker que puede ser replicado e insertado en diversas situaciones comunicativas manteniendo su función discursiva.

Este artículo, además, demostró que no existen marcadores conversacionales propiamente orales o propiamente escritos, sino que un marcador puede usarse tanto en una interacción oral como en algunos pasajes de ciertos géneros escritos y encontrar su forma-meme en géneros digitales como Whatsapp. Esta categoría de marcador-meme revela la resemiotización del marcador ahre cuando se reelabora en otros modos semióticos; es decir, cuando las permisibilidades del modo verbal no logran comunicar significados semánticos y pragmáticos, otros recursos semióticos hacen posible comunicar esos significados, y así descubrimos cómo un marcador se gestualiza (Magadán, 2021). 
Teniendo en cuenta estos resultados parciales, esta investigación reveló que el estudio de los marcadores en línea requiere ser abordado desde una perspectiva multimodal que permita comprender los discursos como paisajes semióticos complejos. Coincidimos con Kress (2003, p. 43) en que, a partir del potencial transformador de las tecnologías digitales en las prácticas de comunicación contemporáneas, se torna necesario pensar una propuesta superadora de la dicotomía oral/escrito para concebir un continuum en el que muchas veces no es posible aislar un modo de otro. Trabajos desde enfoques semejantes permitirán examinar las continuidades y discontinuidades de otras unidades semánticas y pragmáticas, yno solo de los marcadores del discurso, en el ida y vuelta que realizan los hablantes entre distintos géneros discursivos y modos.

\section{Referencias}

Alvarado, M., \& Yeannoteguy, A. (1999). La escritura y sus formas discursivas. Buenos Aires: Eudeba.

Blanche-Benveniste, C. (1998). Estudios lingüísticos sobre la relación oralidad-escritura. Barcelona: Gedisa.

Blommaert, J. (2015). Meaning as a nonlinear effect: The birth of cool. Working Papers in Urban Language \& Literacies, 138, 1-15.

Bonnin, J. E. (2014). To speak with the other's voice: Reducing asymmetry and social distance in professional-client communication. Journal of Multicultural Discourses, 9(2), 149-171.

Borzi, C. (2014). Marcadores del discurso de Buenos Aires. Cuadernos de la ALFAL, 5, 13-42.

Briggs, C. L., \& Bauman, R. (1996). Género, intertextualidad y poder social. Revista de investigaciones folclóricas, 11, 78-108.

Briz, A. (1998). El español coloquial en la conversación. Esbozo de pragmagramática. Barcelona: Ariel.

Cantamutto, L. (2013). La recursividad de las interacciones contemporáneas. Límites teóricometodológicos del estudio de los SMS como conversación. Revista de Ciencias Sociales de la Universidad Nacional de Quilmes “Al abordaje de la comunicación contemporánea. Sociedad y cultura en los mundos de la mediación digital”, 23, 83-104.

Cantamutto, L., \& Vela Delfa, C. (2016). De participante a observador: el método etnográfico en el análisis de las interacciones digitales de Whatsapp. Tonos Digital, 31, 1-22.

Cantamutto, L., \& Vela Delfa, C. (2020). Mensajes, publicaciones, comentarios y otros textos breves de la comunicación digital. Tonos digital, 38, 1-27.

Cassany, D. (1989). Describir el escribir. Barcelona: Paidós.

Dawkins, R. (1976). O gene egoísta. São Paulo: Companhia das Letras.

Di Tullio, Á., \& Kornfeld, L. (2013). Marcas de modalidad epistémica en el registro coloquial. In A. Di Tullio (Ed.), El español de Argentina: estudios gramaticales (pp. 83-103). Buenos Aires: Eudeba.

Eckert, P. (2004). Adolescent language. Language in the USA: Themes for the Twenty-first Century, 6, 58-75. 
Eckert, P. (2006). Communities of practice. Encyclopedia of Language and Linguistics, 2, 683-685.

Escandell Vidal, M. V. (1996). Introducción a la pragmática. Madrid: Ariel.

García Negroni, M. M. (2012). Ma qué" y "otra que”: dos marcadores de descalificación del español rioplatense. Anuario de lingüística hispánica, 28, 57-75. http://uvadoc.uva.es/ handle/10324/11580.

García Negroni, M. M. (2014). Marcadores del discurso: perspectivas y contrastes. Buenos Aires: Santiago Arcos.

Halliday, M. (1978). El lenguaje como semiótica social. México: Fondo de Cultura Económica.

Hine, C. (2000). Etnografía virtual. Barcelona: Nuevas Tecnologías y Sociedad. Editorial. https://doi.org/10.4135/9780857020277.

Jewitt, C. (Ed.). (2009). The Routledge handbook of multimodal analysis. New York: Routledge.

Knobel, M., \& Lankshear, C. (2005). Memes and affinities: Cultural replication and literacy education (pp. 1-22). Miami: NRC.

Kornfeld, L. M. (2013). Atenuadores en la lengua coloquial Argentina. Lingüística, 29(2), 17-49.

Kornfeld, L. M. (comp.). (2014). De lenguas, ficciones y patrias. Los Polvorines: Universidad Nacional de General Sarmiento.

Kress, G. (2003). Literacy in the new media age. Londres: Routledge. https://doi.org/10.4324/ 9780203299234.

Kress, G. (2005). El alfabetismo en la era de los nuevos medios de comunicación. Granada: Ediciones El Aljibe-Enseñanza Abierta de Andalucía.

Kress, G. (2009). Multimodality: A social semiotic approach to contemporary communication. Londres: Routledge. https://doi.org/10.4324/9780203970034.

Kress, G. R., \& Van Leeuwen, T. (2001). Multimodal discourse. The Modes and Media of contemporary communication. London: Arnold.

Kuguel, I. (2014). Los jóvenes hablan cada vez peor. Descripción y representaciones del habla juvenil Argentina. In L. Kornfeld (Ed.), De lenguas, ficciones y patria (pp. 45-73). Los Polvorines: Universidad Nacional de General Sarmiento.

Liddicoat, A. J. (2007). An introduction to conversation analysis continuum. New York: The Tower Building.

Lorendo, R., \& Picone, M. (2012). Los marcadores discursivos en Twitter: el uso de\# ponele como marca de ironía. Comunicación, 25, 26-43.

Lyons, J. (1977). Semantics. London: Cambridge University Press. https://doi.org/10.1017/ cbo9781139165693.

Magadán, C. (2021). Textos figurados: apuntes sobre la escritura multimodal en intercambios adolescentes. Enunciación, 102-119. https://revistas.udistrital.edu.co/index.php/enunc.

Mancera Rueda, A., \& Placencia, M. E. (2011). Los marcadores del discurso en la construcción de habla de contacto en un contexto de servicio en el español peninsular. Revista internacional de lingüística iberoamericana, 18, 145-172.

Martín Zorraquino, M. A., \& Portolés, J. (1999). “Los marcadores del discurso”. In I. Bosque, \& V. Demonte (Eds.). Gramática descriptiva de la lengua española (pp. 4051-4213). Madrid: Espasa Calpe.

Ong, W. (1982). Oralidad y escritura. Tecnologías de la palabra. Argentina: FCE.

Pérez Salazar, G. (2017). El meme en Internet, identidad y usos sociales. Coahuila: Fontamara.

Portolés, J. (2004). Pragmática para hispanistas. Madrid: Síntesis.

Scollon, R., \& Scollon, S. (2004). Nexus analysis: Discourse and the emerging internet. Londres: Routledge. https://doi.org/10.4324/9780203694343. 
Shifman, L. (2013). Memes in a digital world: Reconciling with a conceptual Troublemaker. Journal of Computer-Mediated Communication, 18, 362-377.

Shifman, L. (2014). Memes in digital culture. Cambridge: The MIT Press.

Tannen, D. (1982). The oral/literate continuum in discourse. In D. Tannen (Ed.), Spoken and written Language: Exploring orality and literacy (pp. 1-16). Norwood, NJ: Ablex. https://doi.org/10. 2307/413530.

Varis, P., \& Blommaert, J. (2015). Conviviality and collectives on social media: Virality, memes, and new social structures. Multilingual Margins: A Journal of Multilingualism from the Periphery, 2(1), 31-31.

Verschueren, J. (1999). Para entender la pragmática. Madrid: Gredos. 